\title{
Industrial Revolution 4.0 Through the Tropical Forest: Empowering State Capability of Indonesia
}

\author{
Yunita Asmawati ${ }^{1(*)}$, Syamsuri $^{2}$, Puput Ratnasari ${ }^{2}$ \\ ${ }^{1}$ Government Science Department, Faculty of Social and Science, Universitas Palangka Raya, Jl. Yos Sudarso,Palangka \\ Raya, 73111A, Kalimantan Tengah, Indonesia \\ ${ }^{2}$ State Administration Science Department, Faculty of Social and Science, Universitas Palangka Raya, Jl. Yos Sudarso, \\ Palangka Raya, 73111A, Kalimantan Tengah, Indonesia \\ *Corresponding author. Email: yasmawati80@gmail.com
}

\begin{abstract}
The immensity of the Industrial revolution 4.0 phenomena has been spreading the globe. The tropical forest of Indonesia becomes one crucial capability. Even though the forest degradation triggers a domestic and international conflict. Hence it is suing for a big impact on the domestic environment and the entire world as well. Furthermore, it is altered to characterize the state by a peace over the 4.0 era. Howsoever human being has nature to cooperate and live in peace.
\end{abstract}

Keywords: Industrial revolution 4.0, peace, conflict, cooperation, forest, forest degradation

\section{INTRODUCTION}

The Internet transformation of the digital industry is still in progress, but artificial intelligence, big data, and connectivity indicate the certainty of a new round of digital revolution (Roblek, Mesko and Krapez, 2016: $1)$. This is how the nature of life of the industrial revolution 4.0 or the fourth of the industrial revolution has been coped as one intertwined to nature. Human well-being could not live separated from nature. As the forest essentially one of the environmental highlights in the global interest in which human well-being has been supported.

Nowadays, where the 4.0 of the industrial revolution has been spreading around the world, the human being cannot avoid the importance of forest sustainability for the life of human. The forest contribution to the life of human beings encompasses the very substantial needs of life. As a pleasuring of breath in, where there is no forest fire or the land is happening. Additionally, there are the needs of no victims of forest access as an impact of unfair forest management.

It simply becomes a way to improve the capability of a state. As capability cannot come from one source of capability, it does encompass a variety of sources of a state. Then it back to the chained of a number of actors interest. Especially the chained of actors in the international political constellation.

However, in the last decades, Indonesia goes through the disadvantages experience from forest fire in some regions as Central Kalimantan as one of the largest tropical forests. Regardless, it means to the purposing of the forest as one crucial state capability, especially when it usually happens in the summertime period. Even though Indonesia has a number of cooperation regarding the forest and in order to have a sustainability life of the environment. In this case, the matter is how the forest could be sustained as a state capability as yet the persisting of disadvantage experience does not have a workaround. It becomes inharmonious to the theory when the forest keeps degradation. As capability theoretically, places the forest to be one source which the state needs to improve.

\section{LITERATURE REVIEW}

\section{The Nature of Industrial Revolution 4.0}

The period of the fourth industrial revolution will be marked by the full automation and digitization processes, and the use of electronics and information technologies (IT) in manufacturing and services in a private environment (see Roblek, Mesko, and Krapez: 2016). On the one hand, the quality of the changes can be seen in the fact that the whole production process is managed and supervised in an integrated way, and is combined, as yet flexible (Nagi and Olah, 2018: 2). This condition could be said that some chain and linkage has been tightly to connect every data and work. The key point of development and integration of human in using the three fundamental system of 4.0 of the industrial revolution. These three things as cyber, the Internet of Service and the Internet of Things have led the condition to the emergence of changes in a role as well as human behavior.

\section{Cooperation}

Cooperation has its nature linkage to the conflict condition of actors. It harmoniously to Keohane on how 
cooperation has taken place through a conflict between or among states. According to Keohane (Little 2006: 91-100) that there has been a conflict in the process of interaction between or between actors. The following Figure captured the process of cooperation.

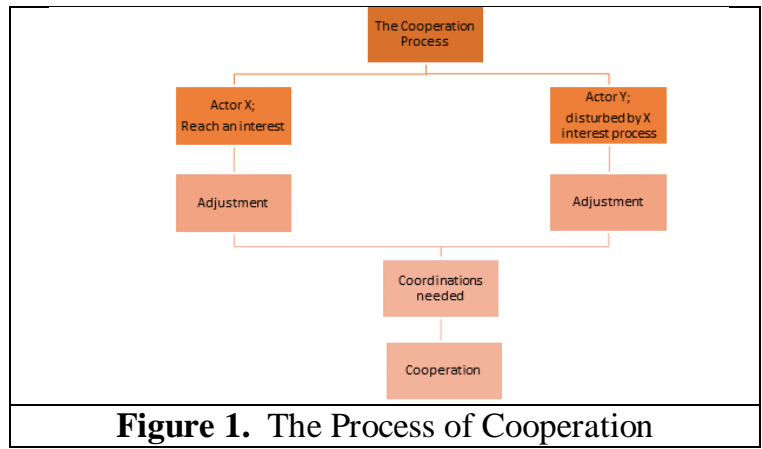

The conflict has occurred prior to collaboration occurs between two or more actors. For example, when interest has achieved by an actor without regard to the interests of other actors. Then the achievement of interests has become a barrier for other actors in achieving interests. Due to the condition, Keohane had demonstrated the call for an adjustment (Little 2006: 91-100). The conditions can be more different when both actors have knowledge about this inequality a will to make policy adjustments as well. The certain policy adjustments could be a potential one in reducing the emergence of greater conflict.

The conditions, after all, in this phase have been decisive for the realization of cooperation. Because when the two actors have overcome this condition through adjustments, a coordination process will be made in terms of adjusting policies. However, the adjustment was needed to be the relevant ones for each national interest. This coordination process according to Keohane has led these actors into a condition called cooperation (Little 2006: 91-100).

\section{State Capabilities}

Theoretically, the capability of a state as a manifestation of assets. It has been a thing that always

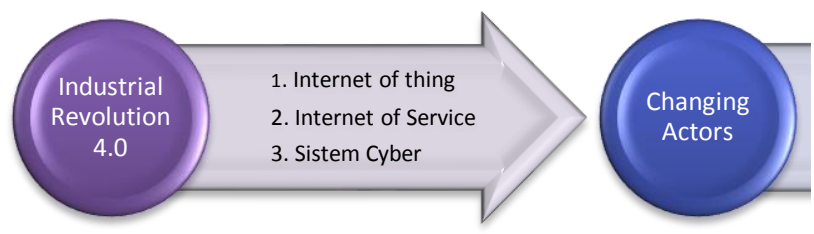

Figure 2. This figure captured the way of thinking on how the Industrial Revolution related to the sustainability of forest and the result of peace. looked forward of a state in the short term as well as a long term. One closer look as Brighi and Hill stated that capabilities are resources that are made operational but which are not yet translated into the specific instruments which may be applied in practical politics, such as propaganda or the use of force (Brighi and Hill, 2008: 130). Another explanation is about the implementation of the capability by Andrew, Pritchett and Woolcock. One of the reasons of scaling up the policies and program are denoted from the presence of the potential capability implementation. Conversely, the "perverse of incentive", "low capacity" and the lack of "political will" become the most reason why the state or individual has a weak capability implementation (Andrew, Pritchett and Woolcock, 2017: 2). These two concepts of capability have a line to the resource in a state.

\section{The Forest Sustainability}

The sustainability of the forest has become one of the most impacts on global climate change. One of the International Organizations (IOs) as The United Nations Framework Convention on Climate Change (UNFCCC) emphasized forest as one of the important elements in reaching sustainable development (UN REDD+ 2010). An example of this emphases was REDD+ or Reducing Emission from Deforestation and Forest Degradation Plus. REDD+ encouraged as one international regime on environmental.

Regarding deforestation has been said by Daguma and Atela (Daguma and Atela, 2019: 6) that: "Deforestation is the conversion of forested areas to non-forest land use such as arable land, urban use, logged area or wasteland". Furthermore, Daguma and Atela (Daguma and Atela, 2019: 6) explain that: "In developing countries, deforestation and forest degradation debates attribute forest losses to the interactions between multiple factors on livelihoods and development". How the concept has been said by Daguma and Atela has a linkage to the REDD+ which the most has been implemented in some developing countries.

\section{METHOD}

This paper made a contribution to the life of knowledge, especially in social and political science. It tried to promote the environment (forest as one of the focus areas) through the theory of industrial revolution 4.0. It elaborated on the forest as capability and the relevant theory through the qualitative method. Furthermore, it related the capability to the changing actor in the international and local constellations. As an impact of the industrial revolutions 4.0. The changing actors had become a crucial one to see how the forest could be sustained as capability of a state in Indonesia. It particularly in Central Kalimantan. 


\section{RESULT AND DISCUSSION}

Result

Changing Actor and Cooperation Linkages

The birth of non-human role opportunity in this fourth industrial revolutions has been changing the actors to play in the international constellations. If the first revolution emerging the only state as the actors in international relations, so the wave of globalization has been bringing the new actor to take part. Some actors besides the state are International Organizations (IO) where there are divided into Governmental Organizations to Non-Governmental Organizations. Some other actors are individual actors and the system actor. Indeed, humans are the mere actors, as human play the role in motorizing both the system and the International Organizations.

The changing of actors in international relations can witness how technology took part in numerous p00roles of human life. As one crucial thing implied the involvement seen from the key element of the industrial revolution 4.0. It signified the used of cyber and internet as a thing and service (Roblek, Mesko and Krapez, 2016: 1). Both the internet of things and services could easily replace the role of humans.

Hence, the industrial revolution 4.0 had a possibility of changing the existing actor in the international constellation. Although the Industrial Revolution 4.0 characterized the condition of how human as yet had a role of controlling the process of work. As et the Existence of power generating technology as one that chained the essence of work to the effectiveness and efficiency needed humans in driving the destination.

Along with this, for instance it denoted how the smart device or another new modern technology used by humans in measuring the emission of countries. Another important example could be witnessed by the technology of how the wood of forest detected as a proper one to be used as timber in a feasible age. Assuredly, it assisted in strengthening implementation law and policy regarding forest management due to the illegal logging.

Consequently, the role of humans, in managing the forest as one of the notable issues of the environment, initiate to be shifted. However, the Industrial revolution of 4.0 environment was not disappearing the human role, as the technology run in an automatically system without a human driving.

Above all the shifted occurred changing condition by the replacement of the internet and the cyber power of technology. Nevertheless, it is not a mere advantage for the human being. Additionally, it becomes a challenge to the human being as the changing role.

The smart device has an opportunity to assist humans in many kinds of activities. Power-generating technology such as robotization and automation has long existed. The Internet, however, revolutionizes numerous processes of the organization by networking robotic and automated devices. The development of the internet and technology has been created a continuous network of people, machines and companies, and through the continuous sharing of value-creating processes.

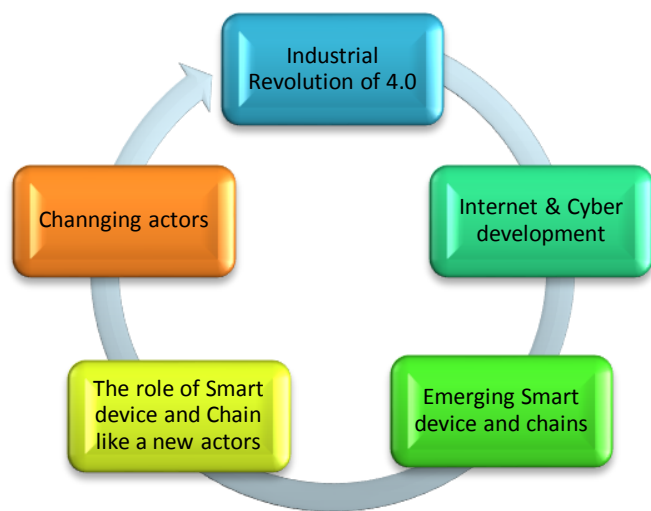

Fig. 3. The figure explained the chain of the industrial revolution of 4.0 to the changing actors

The certain condition had changed the cooperation environment among human life. If the human was a central actor who was playing in all aspects of life, then the device chain of technology took part in the chance of role in the industrial revolution era of 4.0. If the human had become the mere actors in determining the sustainability life of the forest, then the human-assisted by the technology and in some cases, human shared the role to the device. All of these are in order to have the effectiveness of work. The presence of forest in this industrial complex 4.0 era was not merely a challenge of the global workout. It was an effective way to create or event empowering state peace through cooperation. Every single activity was related to the internet as an answer to how the industrial revolution of 4.0 impact the state environment.

\section{Sustainable Forest to The Global Peace}

Deforestation and forest degradation that have occurred in the last few decades, especially in Indonesia can set a precedent for understanding how fundamental points push out the principles of sustainable forest development. The concepts of deforestation and forest degradation, as written in the literature review, can be a way to read forest sustainability expectations. One of the points intended especially when stating how forests have grown to be part of the global problem. That refers to the conversion of forest areas held in areas that are prohibited from conversion. As one of the reasons, where the prevention of forest conversion carried out, it was the same as an alternative way to make the life of forest management completely direct to sustainable development.

This can be said of how certain actors try to gain interest through the sophistication of nuance 4.0 while this has been an obstacle to forest sustainability. It has become unbalanced. It has become one reason for this 
imbalance that addressed a country to a slowly step in reaching towards peace. This happened if humans remain the conditions and interests that do not provide a balance to the environment. It can be said that it has become the dynamic that raised various issues leading to a conflict. Hence Keohane's idea of making an adjustment has been a must and relevant in order to make room for other lives to achieve sustainability.

Furthermore, the condition of peace has become a finding of a condition of wherewith space for justice provided both for humans and for non-humans such as the environment. Especially when the involvement of various smart devices provides benefits for humans. Therefore, the reciprocity for an environment is to protect it from damage.

\section{Discussions}

Facing the nowadays industrial revolution 4.0 challenges elements of a state and individual in a rethinking of what is expected and desired from the existence of smart Internet-connected devices. Even the impact of these smart internet-connected devices has changed many conditions of human life. Since the changing scope has been spreading from local to global change and the matter has been required as the intermestic affair.

Some of the changing example are on how actors changing. The impact to the forest sustainability as one of the fundamental supports for the entire important modern technologies. Another critical impact of these conditions of forest sustainability, where forest as one of the state capabilities, is the emerging of peace event conflict. How it made a solution for an effectiveness matter, has similarly become a crucial determination to a direction of peace or conflict. Since the chain of the era to conflicts and or peace are like an interchangeable condition of social life. How fast the change will take place depends on how fast the technology is going to develop, how it will be accepted and what desire there is for investment (Nagi and Judit, 2018: 20) and indeed it has a linkage to the capability of the state.

Then understanding the era of Industry 4.0 where the value has been beyond the globalization era, as Internet-connected technologies have been empowering by the field of study. Its contemporary study outlines an important theoretical contribution to be understanding.

This kind of finding was not solely an experience without a theoretical base based, even though on the review of the literature. Finally, the value of the Internet of Things or IoT significantly moves to a high level than is reflected by the number of devices. Undoubtedly the need for the sustainability of an environment also move to a high level to save the world has a sustainability balance.

\section{CONCLUSION}

If there were a phenomenon where the emerging of the new actors appeared after a long decades state became the only actor in the international constellation, then the industrial revolution almost did the same way. The new role in a new era had been one crucial thing. Although it emerged almost driving the same role as humans before, however, humans have their proper capability in making a decision regarding the sustainability of the smart device of the chain.

Consequently, the changing environment led the changing condition of peace and conflict. The peace among humans or among actors has been dynamically analysed in numerous fields of study, the era of industrial revolution 4.0 demonstrated the different nuanced of peace as well as the conflict. Despite the linkage environment created dynamically among actors, there was a notable point to be the future analysed. The crucial point was about how the peace created between humans and humans in doing the work, as well as between humans and machines. The emerging role of the non-human in faster and correct the task of work become one notable effective to the state environment. These conditions simply became a trigger for a peace between human, however, the stable of peace or unstable of peace had become a part of another crucial analysis in the future. It undoubtedly enriches the knowledge of the field of study.

\section{REFERENCES}

7.1. References to electronic-only journals.

[1] Daguma, Lalisa A dan Joanes Atela dkk. 2019. Deforestation and Forest Degradation as an Environmental Behavior: Unpacking Realities Shaping Community Actions. (Online), dalam www.mdpi.com/journal/land. Land 2019,8,26; doi:10.3390/land8020026.

[2] Giri Tejaswi. 20017. Manual on Deforestation, Degradation, and Fragmentation Using Remote Sensing and GIS; Strengthening Monitoring, Assessment and Reporting (MAR) on Sustainable Forest Management (SFM) in Asia (GCP/INT/988/JPN). Forest Department - Food Agriculture Organizatio of UN (Online).

[3] Nagi, Judit and Judit Olah. 2018. The Role and Impact of Industry 4.0 and the Internet of Things on the Business Strategy of the Value ChainThe Case of Hungary. In Sustainability 2018, 10, 3491; doi:10.3390/su10103491 HYPERLINK

"http://www.mdpi.com/journal/sustainability" www.mdpi.com/journal/sustainability. Accessed on October 2019.

[4] Roblek, Vasja, Maja Mesko and Aloj Krapez. 2016. A Complex View of Industry 4.0. Sage Open April-June 2016: I-II (C) The Author (s) 
2016 DOI: $\quad 10.1177 / 2158244016653987$. sgo.sagepub.com (online). Accessed on October 2019.

[5] Dominici, G., Roblek, V., Abbate, T., \& Tani, M. 2016. "Click and drive": Consumer attitude to product development. Towards future transformations of driving experience. Business Process Management Journal, 22, 420-434. doi:10.1108/BPMJ-05-2015-0076. Accessed on October 2019.

7.2. References to books, conference proceedings and reports.

[1] Andrew, Mat, Lant Pritchett and Michael Woolcock. 2017. Building State Capability; Evidence, Analysis, Action. United Kingdom: Oxford University Press.

[2] Keohane, Robert O. 1984. "After Hegemony: Cooperation and Discord in the World Political Economy" from Little, Richard dan Michael Smith. 2006. Perspectives on World Politics. Third Edition. London: Routledge \& Francis Group

[3] Smith, Steve. 2008. Amelia Hadfield dan Tim Dunne. Foreign Policy; Theories, Actor, Cases. Oxford, United Kingdom: Oxford University Press.

[4] UN REDD+. 2010. Memorandum of Understanding between Government of the Republic of Indonesia and the United Nation System on the Framework for Cooperation with and Support for the National REDD+ Programme in the Republic of Indonesia.

[5] The Convention on Biological Diversity. 2011. Conference of the Parties Decision X/2: Strategic Plan for Biodiversity 2011-2020. Available online: www.cbd.int/decision/cop/?id=12268 (accessed on October 2017). 